\title{
LA RESOCIALIZACIÓN DEL REINCIDENTE EN LOS FUNDAMENTOS DE LA SENTENCIA PENAL. CASO JUZGADOS PENALES DE TACNA. PERIODO 2013-2014.
}

\author{
THE RESOCIALIZATION OF THE REINCIDENT IN THE FUNDAMENTALS \\ OF CRIMINAL JUDGMENT. CASE OF PENAL COURTS OF TACNA. PERIOD \\ 2013-2014.
}

JOSE SERGIO AGUILAR CORONEL 1

\section{Resumen}

El problema planteado surge cuando se trata de condenar a una persona reincidente del delito, las fundamentaciones de la sentencia - respecto a la justificación y calidad del agente reincidente -, son escasas. No se justifica el fin de la pena del sentenciado reincidente, teniendo en cuenta que el derecho penal moderno establece que el fin de la pena es la resocialización del individuo. La investigación se desarrolló conforme a 20 sentencias penales del Poder Judicial de Tacna, el cual permitió conocer a cabalidad la realidad de los pronunciamientos y fundamentos de los jueces penales de esta jurisdicción. Al lograrse los objetivos, ésta investigación cobra importancia y relevancia jurídica por cuanto incrementa el saber de la ciencia en materia jurídica con aportes empíricos comprobados científicamente sobre el fundamento de la resocialización como fin de la pena para los reincidentes del delito. Metodológicamente, la investigación es de tipo cuantitativo y cualitativo. Asimismo, la presente investigación será netamente documental (sentencias condenatorias). El instrumento de medición está representada por las ficha de información de la sentencia. Se concluye que la fundamentación de sentencias penales respecto a la resocialización como fin de la pena para los reincidentes, en los Juzgados Penales de Tacna, contienen una motivación insuficiente.Las sugerencias van dirigidas a mejorar las fundamentaciones de las sentencias y sobre la aplicación de penas a los reincidentes el Congreso de la república deberá tomar acciones para modificar sobre la reincidencia.

Palabras claves: Fundamentación de sentencias.

\section{Abstract}

The problem arises when it comes to condemn a recidivist of the crime, the grounds of the sentence - with respect to the justification and quality of the recidivist agent -, are scarce. The end of the sentence of the sentenced recidivist is not justified, bearing in mind that modern criminal law establishes that the purpose of punishment is the re-socialization of the individual. The investigation was carried out in accordance with 20 criminal judgments of the Judiciary of Tacna, which allowed to fully know the reality of the pronouncements and grounds of the criminal judges of this jurisdiction. When the objectives are achieved, this research acquires importance and legal relevance because it increases the knowledge of science in legal matters with scientifically proven empirical contributions on the basis of re-socialization as the end of the penalty for repeat offenders. Methodologically, the research is quantitative and qualitative. Likewise, the present investigation will be purely documentary (condemnatory sentences). The measurement instrument is represented by the statement information card. It is concluded that the foundation of criminal sentences regarding resocialization as the end of the sentence for the recidivists, in the Criminal Courts of Tacna, contain an insufficient motivation. The suggestions are aimed at improving the grounds of the judgments and on the application of penalties. to the recidivists the Congress of the Republic should take actions to modify on recidivism.

Keywords: Foundation of sentences. Recidivism. Resocialization

1 MAGÍSTER EN DERECHO CON MENCIÓN EN CIENCIAS PENALES 


\section{INTRODUCCIÓN}

Consideramos que el problema es la postura que adopta nuestra legislación penal sobre la reincidencia. Consideramos que no es suficiente señalar solamente los artículos pertinentes para justificar la pena del reincidente, sino, ésta debe ser con una fundamentación, motivación y justificación minuciosa si se trata de un reincidente. La problemática esencial es la fundamentación de las sentencias penales para los reincidentes, estos hechos no pueden ser ajenos a la problemática de la agravación de penas para los reincidentes.

La fundamentación y motivación de una sentencia penal constituye la parte medular de la decisión tomada por parte de los jueces penales. Se permite así, conocer las razones de la noculpabilidad, o las razones de la condena, cualquiera fuere el caso. La persona condenada debe tener garantizado poder conocer la apreciación que hizo el juez de los hechos y de los medios de prueba, además de la interpretación y aplicación concreta hecha de la norma transgredida. El acusado no solo tiene la satisfacción de conocer porque razón es condenado, sino que al conocerlo, junto al procedimiento seguido, es lo que le permite ejercer, tanto ante el segundo grado de jurisdicción como en casación, sus medios de defensa contra la sentencia que le fue adversa. El Nuevo Código Procesal Penal en su artículo 394 exige, al elaborarse y redactarse la sentencia, entre otros, cumplir con determinados requisitos que determinan que el imputado efectivamente conozca sobre los hechos por los que se le condena. Entre estos está: enunciar el hecho objeto del juicio y su calificación jurídica; exposición de los motivos de hecho y de derecho en que los jueces fundan sus votos, pudiendo adherirse a las consideraciones y conclusiones formuladas por quién vota en primer término; determinación precisa y circunstanciada del hecho que el tribunal estima acreditado judicialmente y su calificación jurídica. Al respecto, el inciso 3) del citado artículo, expresa que la sentencia contendrá: "La motivación clara, lógica y completa de cada uno de los hechos y circunstancias que se dan por probadas o improbadas, y la valoración de la prueba que la sustenta, con indicación del razonamiento que la justifique".

Sin embargo, cuando se trata de condenar a una persona reincidente del delito, las fundamentaciones de la sentencia - respecto a la justificación y calidad del agente reincidente -, son escasas. No se justifica el fin de la pena del sentenciado reincidente, teniendo en cuenta que el derecho penal moderno establece que el fin de la pena es la resocialización del individuo. Si bien, la pena para el reincidente debe ser aplicada conforme a ley, es decir, como circunstancia agravante y por ende el incremento de la pena, las sentencias penales no fundamentan ni justifican adecuadamente sobre estos hechos. Debemos dejar en claro que tanto la Constitución Política (Art. 139, inc. 5) y el Nuevo Código Procesal Penal dan las pautas esenciales sobre la fundamentación.

Cabe reflexionar que la resocialización y reinserción, son temas amplios que está ligado al rol principal del Estado. Actualmente el Estado no cumple adecuadamente con su función y política de prevención y protector de la sociedad, donde el sujeto reincidente es difícilmente tratado, resocializado y reinsertado a nuestra sociedad, ya que bajo a luz de las recientes modificaciones legislativas la Ley $\mathrm{N}^{\circ} 30076$ y posteriormente el Decreto Legislativo $N^{\circ} 1181$, es mucho más difícil cumplir con tales fines de la pena para el reincidente, ya que reafirmar al reincidente como un tema de agravante, donde no tiene oportunidad de resocializarse ni reinsertarse en la sociedad, en la presente ley no es participe para tener una oportunidad de acogerse en esta ley, siendo más severa aun la sanción para los reincidentes, claramente estigmatizado estas personas sin tener en cuenta sus derechos constitucionales y universales como seres humanos.

Agudo Fernández refiere que "(...) el legislador ha tenido una inmejorable oportunidad para escoger la prevención de la recaída a través de las medidas de seguridad, sin embargo, ha optado en su lugar por castigar más duramente al reincidente. Tal decisión no es afortunada si, como punto de partida, se admite que la más eficaz protección contra el crimen viene dada más por su prevención que por su represión." Vega Quesada concluye que "(...) la reincidencia que se contempla en el Derecho Penal costarricense es una figura de Derecho Penal de autor que no es propio de un modelo cognitivo-garantista, como el costarricense. Es una figura propia de estados autoritarios y de un Derecho Penal de autor, ya que se fija no en el hecho cometido sino, en el sujeto. (...)". Asunción Ramírez Opina que "De la jurisprudencia constitucional revisada queda claro que el Tribunal Constitucional peruano diferencia el régimen penitenciario, del 
tratamiento penitenciario. No obstante estas condiciones deberán necesariamente configurarse en armonía con las exigencias de "reeducación", "rehabilitación" y "reincorporación" del penado a la sociedad"."

La reincidencia para Cabanellas "Reincidencia es la repetición de la misma falta, culpa o delito; insistencia en los mismos. Estrictamente hablando se dice que reincidencia es la comisión de igual o análogo delito por el reo ya condenado. Agrava la responsabilidad criminal por demostrar la peligrosidad del sujeto, la ineficacia o desprecio de la sanción y la tendencia a la habitualidad" (Cabanellas Tomo VII: 112). Campos (1984) señala que "al decir tal o cual individuo reincidió, siempre nos referimos cualificando un volver a hacer algo impropio o ilícito." (p. 212). Es así que una persona ha vuelto ha comportarse antisocialmente o contrariando normas morales, o de la religión e incluso cometiendo nuevos hechos delictivos. Al respecto, García (2012) refiere que doctrinariamente hay reincidencia "cuando al delinquir, el culpable hubiese sido condenado ejecutoriadamente por un delito de la misma naturaleza, pero también se señala que hay reincidencia si la condena ejecutoriada anterior lo fuera por otro delito al que la ley señala de igual o menor pena o por dos o más a los que aquella señale pena menor". Jiménez de Asúa considera que la reincidencia constituye un concepto tendiente a desaparecer, para ser substituido por el de la habitualidad. Los problemas e implicancias de la reincidencia son diversos, tal como señala Serrano (1976): "La recaída o reincidencia en el delito es un problema que viene preocupando no solo a los penalistas en cuanto pretenden justificar la agravante en base a diversos criterios-, sino a los criminólogos con referencia a la motivación-, a los penitenciaristas -por los problemas de tratamiento que plantea-, a la propia administración de justicia -en cuanto al notable incremento de la reincidencia-, a los políticos -por el problema social que les crea- $y$, finalmente, a la sociedad en general, por el mayor temor que se le tiene al sujeto que una y otra vez incide en su conducta criminal".

Cruz (2011) señala que "Las manifestaciones doctrinales más críticas frente a la agravante de reincidencia aluden con frecuencia a la vulneración de estos principios y, por ende, a la idea de dignidad de la persona." Sanz-Diez (2013) señala que "si la pena ha resultado ineficaz no resulta razonable insistir en el mismo tipo de respuesta, pero incrementada." La resocialización se define como la recuperación del individuo para la sociedad, elemento central del fin preventivo especial de las penas. Se trata de un concepto difuso, incorporado teóricamente a los fines de la pena sin darle antes un contenido que establezca sus objetivos, límites y métodos. Al respecto, Fernandez (2002) refiere que "La resocialización ha figurado como uno de los principios limitativos del ius puniendi, entendido este como la potestad del Estado para dictar las leyes del Derecho Penal, imponerlas judicialmente y ejecutar las sentencias correspondientes." Medina Cuenca por su parte expresa que el derecho de castigar del Estado ha adquirido rango constitucional y supranacional, cuya problemática en la actualidad atraviesa por la necesaria materialización de ese derecho sin vulnerar los derechos que también ha adquirido el hombre y que le colocan en una situación en la cual puede exigir los mismos y limitar el poder del Estado. Mir Puig ha delineado este principio al señalar que "la ejecución de la pena debe evitar en lo posible sus efectos de socializadores, debe fomentar una cierta noticia con el exterior y proporcionar una adecuada reintegración del recluso a la vida en libertad".

\section{OBJETIVOS}

a) Establecer en qué medida las sentencias penales, se hacen referencia al fin de la pena respecto a los reincidentes.

b) Analizar si en las sentencias penales se utiliza el término resocialización como fundamento respecto a los reincidentes.

c) Advertir si en las sentencias penales existen fundamentaciones jurisprudenciales y doctrinarias respecto a la resocialización del reincidente.

\section{METODOLOGÍA}

Investigación de tipo básica y descriptivo, no experimental. La investigación se realizó en los juzgados penales del Distrito Judicial de Tacna y se tuvo en cuenta las sentencias penales emitidas en los periodos 2013-2014. La población está constituida por 210 sentencias penales condenatorias, elegidas al azar, de los diversos Juzgados Penales del Distrito Judicial 
de Tacna. La muestra estuvo conformada por 20 sentencias penales condenatorias. 10 corresponden al año 2013 y 10 corresponden al año 2014. Se utilizó la técnica del análisis documental con el objetivo de evaluar el cumplimiento de la finalidad de resocialización de las penas como fundamento en las sentencias y su influencia en el nivel de reincidencia de los sentenciados. Se utilizó la ficha de análisis documental.

\section{RESULTADOS}

Se encuentra que 19 sentencias (95\%) penales determinaron que los jueces fundamentan con una motivación insuficiente respecto a la resocialización del reincidente como fin de la pena. El 5\%, representado por una sentencia determinó que dicha fundamentación es altamente insuficiente, por no haber siquiera tenido en cuenta la figura de la reincidencia. El $100 \%$ señalaron que en ninguna medida se utilizó el término resocialización como fundamento. Ninguna sentencia se pronunció sobre los efectos jurídicos-sociales y la trascendencia que tiene la resocialización de la persona y en ninguna medida el término resocialización se utiliza como fundamento respecto a los reincidentes, denotando que la resocialización como fin de la pena no es analizado ni expresado en la sentencia. En el total de las sentencias revizadas no existen fundamentaciones jurisprudenciales ni doctrinarias sobre el acto punitivo del reincidente. Se debe de tener en cuenta que las sentencias que hicieron referencia a la reincidencia, solamente fueron normativas y sin mayores fundamentos.

\section{DISCUSIÓN}

Para iniciar la investigación, nos trazamos como objetivo principal establecer cómo fundamentan los jueces penales del Poder Judicial de Tacna sus sentencias respecto a la resocialización como fin de la pena del reincidente en el periodo 2013-2014. Debido a estos planteamientos, es que se analizó minuciosamente cada sentencia que contenga pronunciamiento sobre un reincidente. Es sabido que la resocialización de la persona que ha cometido un delito compete directamente al Estado, sin embargo ni las leyes ni las autoridades cumplen con este propósito de la resocialización. A pesar de que la Constitución Política del Estado lo determina como un principio elemental y determina que por principio el régimen penitenciario tiene por objeto la reeducación, rehabilitación y reincorporación del penado a la sociedad. Pero como dijimos, no se cumple. Esta situación se ve reflejada en las fundamentaciones de las sentencias penales de los reincidentes.

Agudo (2005) en parte de sus conclusiones señala respecto a la reincidencia como agravante que el legislador ha tenido una inmejorable oportunidad para escoger la prevención de la recaída a través de las medidas de seguridad, sin embargo, ha optado en su lugar por castigar más duramente al reincidente. Tal decisión no es afortunada si, como punto de partida, se admite que la más eficaz protección contra el crimen viene dada más por su prevención que por su represión. Efectivamente, resulta incompatible con la Constitución el hecho de sancionar drásticamente al reincidente. Concluimos que la fundamentación de sentencias penales respecto a la resocialización como fin de la pena para los reincidentes, en los Juzgados Penales de Tacna, contienen una motivación insuficiente. En las sentencias penales, en ninguna medida se hace referencia al fin de la pena respecto a los reincidentes del delito. Las fundamentaciones sobre la resocialización del reincidente son insuficientes, es decir, en ninguna medida el término resocialización se utiliza como fundamento en las sentencias penales. No hay un fundamento normativo, doctrinario ni jurisprudencial referente a la resocialización del individuo ni pronunciamiento adecuado sobre la reincidencia. Se infiere que casi la totalidad del contenido de las sentencias no se pronuncia sobre la reincidencia ni resocialización del sentenciado. En las fundamentaciones de las sentencias penales sobre la reincidencia prima solamente la norma legal señalada en el Código Penal, antes que la fundamentación suficiente y no se tiene en cuenta la valoración y justificación para aplicar la pena al reincidente.

Considerando que en las sentencias penales exista una escasa fundamentación sobre la reincidencia y la resocialización en las sentencias penales, por lo tanto, el Poder Judicial debe elaborar un manual básico de fundamentación de sentencias, el cual deberá contener lo referente a los reincidentes. A nivel jurisdiccional, se debe de 
impartir cursos de capacitación permanente a nivel de jueces y especialistas legales y que tengan como objetivo aunar criterios y métodos que los jueces puedan implementar en la redacción de las sentencias, así como su constante actualización jurídica, teniendo en cuenta la situación jurídica de los reincidentes. A nivel del Congreso, se recomienda investigar y analizar lo concerniente a los fines de la pena para su posterior incorporación legal en la Carta Magna teniendo como principio elemental la resocialización del sentenciado. Para tales efectos, se realizarán coordinaciones entre el Colegio de Abogados de Tacna, las Universidades y el Poder Judicial de Tacna para plantear al Congreso mediante los congresistas electos de esta región, las modificaciones a la norma constitucional.

\section{REFERENCIAS BIBLIOGRÁFICAS}

Presentado: Marzo 2017

Aceptado: Junio 2017

Agudo Fernández, E. "Principio de Culpabilidad y Reincidencia en el Derecho Español". 2005.

Cruz, B. (2011) "Significado de la reincidencia en el derecho penal de menores: del pronóstico de peligrosidad a la culpabilidad. 2011". Defensoría Penal Pública. Santiago de Chile. $\mathrm{R}$ e c u p e r a d o d e : http://www.biblio.dpp.cl/biblio/DataBank/5592. pdf

García, J. (2012) "LA REINCIDENCIA PENAL". $R$ e c u p e r a d o d e : http://www.derechoecuador.com/articulos/det alle/archive/doctrinas/derechopenal/2012/02/ 28/reincidencia-penal

Fernández, J. (2002): "Derecho Penal liberal del hoy. Aproximación a la dogmática axiológica jurídico penal", Ediciones Jurídicas Gustavo Ibáñez, Bogotá.

Jimenez de Asúa. Cit. por RODRIGUEZ, Agustín W. \& GALETTA DE RODRIGUEZ, Beatríz. "Fundamentos de Derecho Penal y Criminología” Editorial Juris. Edic. 2001. p. 221.
Medina Cuenca, Cit. por Barroso Gonzales, José Luis "La Perspectiva Penal de la resocialización: Su comportamiento histórico en Cuba".

Ramírez Parco, Gabriela Asunción. "El ejercicio y limitación de los derechos fundamentales de los reclusos: análisis normativo y de la jurisprudencia emitida por el Tribunal Constitucional”. 2012.

Sanz-Díez, M. (2013) "Reincidencia, habitualidad y profesionalidad en las últimas reformas penales. especial referencia a la delincuencia patrimonial". Estudios Penales y Criminológicos, vol. XXXIII Universidad Rey Juan Carlos. España.

Vega Quesada, Karol. "La Reincidencia como Limitante a la Aplicación del Instituto de la Conciliación, Instituto de la Conciliación, en el Proceso Penal en el Proceso Penal Costarricense". 2009. 